\title{
Prolonged low-dose corticosteroid therapy and osteoporosis in rheumatoid arthritis
}

\author{
V. J. HA JIROUSSOU AND M. WEBLEY \\ From the Rheumatology Unit, Stoke Mandeville Hospital, Aylesbury, Buckinghamshire
}

SUMMARY Thirty-one patients with rhe umatoid arthritis maintained on prednisolone $5 \mathrm{mg}$ daily for an average period of $9 \cdot 4$ years were assessed radiologically to determine the degree of osteoporosis in their spine and peripheral skeleton. They were compared with a control group of 32 rheumatoid patients who had never received corticosteroids. The steroid-treated patients had more severe osteoporosis than the controls, though the difference was not statistically significant. In the female patients the spine appeared to be more sensitive than the peripheral skeleton to the osteoporotic effect of corticosteroids.

Osteoporosis is a recognised complication of rheumatoid arthritis (RA), with juxta-articular involvement occurring in the early stages of the disease. A more generalised form may follow affecting the axial as well as the appendicular skeleton. ${ }^{1-3}$ The pathophysiology of osteoporosis is still unknown, though many aetiological factors have been implicated. ${ }^{4}$ In patients with RA such factors may include immobilisation, poor nutrition, chronic inflammation, and corticosteroid therapy. ${ }^{5}$ The part played by low-dose corticosteroids is not entirely clear, and various studies have produced conflicting results. ${ }^{1}{ }^{6-12}$ A major difficulty has been the lack of accurate and sensitive tests to assess the degree of osteoporosis. Newer techniques, such as the estimation of total body calcium as measured by neutron activation analysis, can provide an objective assessment of osteoporosis. This method, however, cannot give a differential assessment of the various parts of the skeleton. Although radiological methods may have their drawbacks, ${ }^{13}$ they do allow a differential study of the skeletion to be made.

The object of the present study was to investigate the effect of oral prednisolone $5 \mathrm{mg}$ daily on the axial and appendicular skeleton of patients with RA.

\section{Patients and methods}

Thirty-two consecutive outpatients with RA receiving prednisolone $5 \mathrm{mg}$ daily were studied. A further 31 rhe umatoid outpatients who had never had corticosteroids and matched with the first group for age,

Accepted for publication 7 February 1983.

Correspondence to Dr M. Webley, Rheumatology Unit, Stoke Mandeville Hospital, Aylesbury, Buckinghamshire. sex, disease severity, and duration were also studied. None of the patients had clinical evidence or a past history of any disorder likely to affect their skeleton. Such disorders included Paget's disease, osteomalacia, hepatic or renal disease, hyperparathyroidism, thyrotoxicosis, and diabetes. The age, sex, duration, and severity of their disease, drug therapy, duration of prednisolone therapy, and number of postmenopausal years in the female patients were recorded.

The arthritis was graded according to the Steinbrocker's functional inde $x^{14}$ as mild (classes 1 and 2) or severe (classes 3 and 4). Such classification was carried out by the same observer (VH) on all patients. The following biochemical indices were measured: serum calcium, phosphate, alkaline phosphatase (AP), and albumin. Serum alanine transferase (AST) and gamma-glutamyl transferase $(\gamma \mathrm{GT})$ were also measured if the AP was raised. Radiographs were taken with a standard technique by a single $x$-ray machine at the same time of day. The following views were obtained: anteroposte rior view of the right femur, posteroanterior view of the hands, and lateral view of the lumbar spine centred on L3. The cortical thickness of the femur and right middle metacarpal were measured with a ruler and a magnifying glass as described by Barnett and Nordin ${ }^{15}$ (the sum of the thickness of the 'medial' and 'lateral' cortices of the shaft divided by the diameter and multiplied by 100). The points of measurement were the mid point of the metacarpal and $14 \mathrm{~cm}$ from the lesser trochanter along the femur. Only the homogeneous and compact bone was measured. Vertebral body density was graded by the method of Saville $^{3}$ as follows: Grade 1: minimal loss of bone 
Table 1 Clinical details of patients studied

\begin{tabular}{|c|c|c|}
\hline & Steroids & No steroids \\
\hline Number of patients & 32 & 31 \\
\hline Female Patients & 19 & 19 \\
\hline Average age & 59.4 years & 58.5 years \\
\hline Average disease duration & 14.0 years & 12.9 years \\
\hline Severe disease & 9 & 8 \\
\hline $\begin{array}{l}\text { Postmenopausal female } \\
\text { patients }\end{array}$ & 16 & 17 \\
\hline $\begin{array}{l}\text { Average number of years } \\
\text { after menopause }\end{array}$ & 13.8 years & 14.0 years \\
\hline Duration of steroid therapy & 9.4 years & - \\
\hline $\begin{array}{l}\text { Duration of steroid therapy } \\
\text { in males }\end{array}$ & 10.6 years & 一 \\
\hline $\begin{array}{l}\text { Duration of steroid therapy } \\
\text { in females }\end{array}$ & 8.6 years & - \\
\hline
\end{tabular}

Table 2 Metacarpal (MC) and femoral cortex scores

\begin{tabular}{|c|c|c|c|c|}
\hline & \multicolumn{2}{|c|}{ Steroid group } & \multicolumn{2}{|c|}{ Nonsteroid group } \\
\hline & $M C$ & Femur & $M C$ & Femur \\
\hline All patients* & $31 \cdot 6$ & $50 \cdot 9$ & $34 \cdot 6$ & $51 \cdot 9$ \\
\hline Female patients ${ }^{*}$ & $29 \cdot 1$ & $49 \cdot 1$ & $31 \cdot 7$ & $51 \cdot 7$ \\
\hline $\begin{array}{l}\text { Postmenopausal } \\
\text { female patients* }\end{array}$ & $24 \cdot 6$ & $47 \cdot 0$ & $29 \cdot 0$ & $50 \cdot 3$ \\
\hline Male patients ${ }^{\dagger}$ & $37 \cdot 1$ & $54 \cdot 2$ & $39 \cdot 2$ & $52 \cdot 2$ \\
\hline
\end{tabular}

${ }^{*} p>0 \cdot 5 .+0 \cdot 1<p<0.5$.

density; end plates begin to stand out giving a stencilled effect. Grade 2: vertical striations more obvious; end plates thinner. Grade 3: more severe loss of bone density than grade 2; end plates less visible. Grade 4: ghost-like vertebral bone; density no greater than soft tissue; no trabecular pattern. Grades 1 and 2 were classified as mild and grades 3 and 4 as severe osteoporosis.

Spinal radiographs were examined by 2 observers independently, each completing his assessment within a relatively short period of time. On completion results were compared, and if there was a difference of more than one grade a second assessment was made. All the films were studied without knowledge of the patients' clinical details or therapy. Cortical thickness and spinal porosity were assessed independently.

Statistical analysis of the results was carried out by the $\chi^{2}$ test.

\section{Results}

Details of the patients are shown in Table 1. The duration of corticosteroid therapy ranged from 3 to 23 years with a mean of $9 \cdot 4$ years. The biochemical indices of all the patients were normal except for a minimally elevated AP in 5 patients, in 4 of whom the $\gamma$ GT was also raised. Both enzyme abnormalities were considered to be of liver origin as may sometimes be seen in patients with RA. ${ }^{16}$ Table 2 shows the average metacarpal and femoral scores. Patients in the steroid group generally had lower scores, indicating a thinner cortex. However, the difference between the 2 groups was not statistically significant $(p>0 \cdot 5)$. When the postmenopausal female patients of the 2 groups were compared, the difference was slightly greater but still failed to reach statistical significance $(0 \cdot 1<p<0 \cdot 5)$.

The grades of spinal density for all the patients in the 2 groups are shown in Table 3. Severe osteoporosis (grades 3 and 4) was commoner among patients of the steroid group as compared with the control group. This difference, however, was not statistically significant $(0 \cdot 1<p<0 \cdot 5)$. When the female patients of the 2 groups were compared, the difference was greater, but once again it failed to reach statistical significance $(0 \cdot 05<p<0 \cdot 1)$. Similar results were found among the postmenopausal female patients. For male patients the effect of steroid therapy on spinal porosity was even less apparent.

\section{Discussion}

The part played by low-dose corticosteroid therapy in

Table 3 Spinal density

\begin{tabular}{|c|c|c|c|c|c|c|}
\hline & \multicolumn{3}{|c|}{ Steroid group } & \multicolumn{3}{|c|}{ Nonsteroid group } \\
\hline & Normal & $\begin{array}{l}\text { Mild } \\
\text { osteoporosis }\end{array}$ & $\begin{array}{l}\text { Severe } \\
\text { osteoporosis }\end{array}$ & Normal & $\begin{array}{l}\text { Mild } \\
\text { osteoporosis }\end{array}$ & $\begin{array}{l}\text { Severe } \\
\text { osteoporosis }\end{array}$ \\
\hline All patients* & 0 & 16 & $16^{*}$ & 2 & 19 & $10^{*}$ \\
\hline Female patients $\dagger$ & 0 & 6 & $13 t$ & 1 & 11 & $7+$ \\
\hline $\begin{array}{l}\text { Post menopausal } \\
\text { female patients } \dagger\end{array}$ & 0 & 5 & $11+$ & 0 & 10 & $7 \dagger$ \\
\hline Male patients & 0 & 10 & 3 & 1 & 8 & 3 \\
\hline
\end{tabular}

${ }^{*} 0 \cdot 1<\mathrm{p}<0 \cdot 5 .+0 \cdot 05<\mathrm{p}<0 \cdot 1$. 
the aetiology of osteoporosis in patients with RA remains to some extent ill defined. Some studies have shown no increased risk of osteoporosis in corticosteroid-treated patients compared with control groups. ${ }^{181011}$ Others have suggested that lowdose corticosteroids play a significant role in the osteoporosis of RA. ${ }^{6791217}$ The average daily dose in these studies was equal to or less than $10 \mathrm{mg}$ prednisolone or its equivalent. In the radiological studies generalised osteoporosis was assessed by the cortical thickness of one or more of the following bones: metacarpal, radius, femur, and clavicle. There have only been 2 reports ${ }^{16}$ in which the spinal density of patients with RA on long-term corticosteroid therapy was assessed radiologically and compared with that in a group of patients who had never been on such therapy. McConkey et al. ${ }^{1}$ failed to show any effect on the spinal density due to corticosteroids, while Saville and Kharmosh ${ }^{6}$ found that patients with RA over the age of 50 had significantly more spinal osteoporosis if treated with corticosteroids. However, disease severity or duration was not taken into account in the latter study, and McConkey did not group his patients according to their age and sex. Other methods used for the assessment of osteoporosis included photon absorptiometry ${ }^{17}$ and neutron activation analysis, which estimates total body calcium. ${ }^{11}{ }^{12}$ Although these methods are considered to be more sensitive, they cannot demonstrate differential loss of bone density.

Riggs et al. ${ }^{18}$ reported that the central and peripheral skeletons may develop different degrees of osteoporosis, and Howland et al. ${ }^{19}$ described more severe osteoporosis in the axial than in the appendicular skeleton of patients with Cushing's disease. In view of these observations it would seem important to examine both the peripheral and central skeleton independently for the assessment of osteoporosis in patients with RA who have been on long-term lowdose corticosteroid therapy.

We assessed osteoporosis of the peripheral skeleton by measuring the metacarpal and femoral cortex, while osteoporosis of the central skeleton was assessed by examining the third lumbar and adjacent vertebrae. Our results suggest that there is a tendency to more severe osteoporosis in the corticosteroidtreated patients both in the spine and in the periphery. The difference, however, from the control group was not statistically significant. We also noted that in female patients the central skeleton appeared to be more sensitive than the peripheral skeleton to the effect of corticosteroids. This finding would support Howland's observation on the distribution of osteoporosis in patients with Cushing's disease. ${ }^{19}$

Thus it would seem that long-term corticosteroid therapy with doses no greater than $5 \mathrm{mg}$ prednisolone daily does increase the degree of osteoporosis in patients with RA. It would also seem that female patients receiving such therapy run a greater risk of developing spinal osteoporosis. Despite these observations the difference between the corticosteroid and non-corticosteroid groups does not reach statistical significance and it could be argued that the osteoporotic effect of low doses of these compounds is unimportant. Therefore the risk of developing osteoporosis should perhaps not be considered a definite contraindication to the use of low-dose corticosteroids in patients with RA.

Newer techniques such as computed tomography ${ }^{20}$ and dual photon absorptiometry ${ }^{21}$ may in the future give a clearer idea of the exact role of these compounds in the pathogenesis of osteoporosis.

We are grateful to the Arthritis and Rheumatism Council for their generous support.

\section{References}

1 McConkey B, Frazer G M, Bigh A S. Transparent skin and osteoporosis, a study in patients with rheumatoid arthritis. $Q J$ Med 1962; 31: 419-27.

2 Duncan H, Frost H M, Villaneuva A R, Sigler J W. The osteoporosis of rheumatoid arthritis. Arthritis Rheum 1965; 8: 934-54.

3 Saville P D. A quantitative approach to simple radiographic diagnosis of osteoporosis: its application to the osteoporosis of rheumatoid arthritis. Arthritis Rheum 1967; 10: 416-22.

4 Avioli L V, Krane S M. Metabolic bone disease I. London and New York: Academic Press, 1977.

5 Kennedy A C, Lindsay R. Bone involvement in rheumatoid arthritis. Clin Rheum Dis 1978; 3: 403-20.

6 Saville P D, Karmosh O. Osteoporosis of rheumatoid arthritis: influence of age, sex and corticosteroids. Arthritis Rheum 1967; 10: 423-30.

7 O'Brian W M, Samuel B M, Jasini M K, Anderson J A, Boyle J A, Buchanan $\mathrm{W} W$. The role of corticosteroids in causing osteoporosis in rheumatoid arthritis. Arthritis Rheum 1968; 11: 501 .

8 Kennedy A C, Smith D A, Anton H C, Buchanan W W. Generalized and localized bone loss in patients with rheumatoid arthritis. Scand J Rheumatol 1975; 4: 209-15.

9 Kennedy A C, Smith D A, Buchanan W W, Anderson J B, Samuels B B, Jasani M K. Osteoporosis in rheumatoid arthritis. Rheumatology 1974; 4: 25-35.

10 Kennedy A C, Smith D A, Buchanan W W, Anderson J B, Jasani M K. Bone loss in patients with rheumatoid arthritis. Scand J Rheumatol 1975; 4: 73-9.

11 Kennedy A C, Boddy K, Williams E D, et al. Whole body elemental composition during drug treatment of rheumatoid arthritis: a preliminary study. Ann Rheum Dis 1979; 38: 137-40.

12 Reid D M, Kennedy N S J, Smith M A, Tothill P, Nuki G. Total body calcium in rheumatoid arthritis: effects of disease activity and corticosteroid treatment. Br Med J 1982; 285: 330-2.

13 Lachman E. Osteoporosis: the potentialities and limitations of its roentgenologic diagnosis. AJR 1955; 74: 712-21.

14 Steinbrocker O, Traeger C H, Batterman R C. Therapeutic criteria in rheumatoid arthritis. JAMA 1949; 140: 659-62

15 Barnett E, Nordin B E C. The radiological diagnosis of osteoporosis: a new approach. Clin Radiol 1960; 11: 166-74.

16 Kendall M J, Cockel R, Becker J, Hawkins C F. Raised serum alkaline phosphatase in rheumatoid disease. Ann Rheum Dis 1970; 29: 532-40. 
17 Mueller M N, Jurist J M. Skeletal status in rhe umatoid arthritis. Arthritis Rheum 1973; 16: 66-70.

18 Riggs B L, Wahner H W, Dunn W L, et al. Differential changes in bone mineral density of the appendicular and axial skeleton with aging: relationship to spinal osteoporosis. J Clin Invest 1981; 67: 328.

19 Howland W J, Puch D G, Sprague R G. Roentgenologic changes in the skeletal system in Cushing syndrome.Radiology 1968; 71: 69-78.

20 Cann L E, Genant H K. Precise measurement of vertebral mineral content using computed tomography.J Computer Assist Tomogr 1980; 4: 493-500.

21 Krolner B, Neilson S P. Bone mineral content of the lumbar spine in normal and osteoporotic women: cross-sectional and longitudinal studies. Clin Sci Mol Med 1982; 62: 329-36. 